\section{Change of inspired oxygen concentration and temperature in low flow anesthesia}

TO THE EDITOR: For low-flow anesthesia, the anesthesia workstation, monitoring technology and desflurane, sevoflurane, which were a low blood-gas partition coefficient, have gradually been adopted. Low-flow anesthesia is considered effective in maintaining the heat and the moisture of the breathing circuit and preserving the mucociliary function of the respiratory tract. In addition, it is safer and more effective at lowering the economic burden and global warming potential $[1,2]$. We read, with interest, your paper on "Change of inspired oxygen concentration in low flow anesthesia" (Anesth Pain Med 2020; 15: 434-40). We appreciate your results and have some questions to discuss.

We have a few questions about the monitoring and the maintenance of body temperature. How did you maintain and monitor the temperature of the operating room? Was the patient's temperature measured only in the esophagus? What was the depth of the esophageal temperature probe? Depending on the room temperature and the depth of insertion, the body temperature can change with ambient influences, such as blood flow of venous return and inhaled gas temperature [3]. Therefore, the authors used a heated breathing system and a heat moisture exchanger (HME) to heat the breathing circuit. During anesthetic care, the patient's temperature did not show a statistically significant change after 60-75 min of low flow. However, it started increasing significantly after $120 \mathrm{~min}$ of low flow.

In this study, soda lime $\left(\mathrm{CO}_{2}\right.$ absorber $)$ and a standard circular rebreathing circuit with a heated breathing circuit were used. Did you use the HME in the heated breathing circuit? One $\mathrm{CO}_{2}$ molecule, exhaled by the patient, produces two water $\left(\mathrm{H}_{2} \mathrm{O}\right)$ molecules and generates approximately $40^{\circ} \mathrm{C}$ of heat during its reaction with soda lime. The moisture and heat generated by the reaction are sufficient for the patient's humidification and warmth during anesthesia 30 min after induction $[1,4]$. Therefore, if a low-flow system is used, there is no reason to use a heated breathing circuit and HME, sufficient heat and moisture can be maintained without a heated breathing circuit and HME [1-5]. We think that the increased temperature within the circuit is not an advantage but a problem caused by adding the heated breathing circuit and HME during low flow rather than high flow. What do you expect to get if you do not attach either of or both the heating breathing circuit and HME?

Hong Seuk Yang, Dong Ho Park, and Chang Young Jeong

Department of Anesthesiology and Pain Medicine, Daejeon Eulji Medical Center, Medical College, Eulji University, Daejeon, Korea

Corresponding author: Hong Seuk Yang, M.D., Ph.D. E-mail: hsyang@amc.seoul.kr

Received December 8, 2020; Accepted: January 13, 2021 https://doi.org/10.17085/apm.20095

\section{CONFLICTS OF INTEREST}

No potential conflict of interest relevant to this article was reported.

\section{AUTHOR CONTRIBUTIONS}

Methodology: Hong Seuk Yang. Writing - review \& editing: Dong Ho Park. Supervision: Chang Young Jeong.

\section{ORCID}

Hong Seuk Yang, https://orcid.org/0000-0003-2023-8705

Dong Ho Park, https://orcid.org/0000-0002-6587-3756

Chang Young Jeong, https://orcid.org/0000-0002-8830-3406

\section{REFERENCES}

1. Baxter AD. Low and minimal flow inhalational anaesthesia. Can J Anaesth 1997; 44: 643-52; quiz 652-3.

2. Baum JA, Aitkenhead AR. Low-flow anaesthesia. Anaesthesia 1995; 50 Suppl: 37-44.

3. Lenhardt R. Monitoring and thermal management. Best Pract Res Clin Anaesthesiol 2003; 17: 569-81.

4. Parthasarathy S. The closed circuit and the low flow systems. Indian J Anaesth 2013; 57: 516-24.

5. Braz JRC, Braz MG, Hayashi Y, Martins RHG, Betini M, Braz LG, et al. Effects of different fresh gas flows with or without a heat and moisture exchanger on inhaled gas humidity in adults undergoing general anaesthesia: A systematic review and meta-analysis of randomised controlled trials. Eur J Anaesthesiol 2017; 34: 515-25.

This is an Open Access article distributed under the terms of the Creative Commons Attribution Non-Commercial License (http://creativecommons.org/licenses/by-nc/4.0) which permits unrestricted non-commercial use, distribution, and reproduction in any medium, provided the original work is properly cited.

Copyright (C) the Korean Society of Anesthesiologists, 2021 